\title{
Impact of the British Thoracic Society chronic obstructive pulmonary disease guidelines on patients' health status, healthcare resource use and health-related quality of life
}

\author{
Julian F. Guest ${ }^{\mathrm{a}, *}$, Susan J. Varney ${ }^{\mathrm{a}}$, John Diggle ${ }^{\mathrm{b}}$ \\ ${ }^{a}$ CATALYST Health Economics Consultants, 34b High Street, Northwood, Middlesex HA6 1BN, UK \\ b Isca GP Unit, Caerleon, Newport, Gwent, UK
}

Received 10 January 2005; accepted 18 July 2005

\section{KEYWORDS}

Chronic obstructive pulmonary alseass;

COPD;

Resource use;

Quality of life;

SF-36;

St Georges Respiratory

Questionnaire;

BTS Guidelines

\section{Summary}

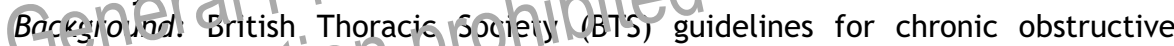
pulmonary disease (안) management are a consensus view and their impact on patient is nonown.

Aijn. To determine the impact of the BTS COPD guidelines on patients' health status, healthcare resource use and health-related quality of life (HRQL).

Design and setting: This was an observational, parallel group, cluster-controlled study comparing patients who were managed in general practices according to BTS guidelines (active practices) or usual care (control practices).

Methods: 13 active and 13 matched control practices participated in the study. Patients completed the St. George's Respiratory Questionnaire (SGRQ) and Short Form 36 (SF-36) at their screening visit and 12 months later during which time their airway function was measured. Healthcare resource use and drug utilisation data during the study period were also recorded.

Main outcome measures \& results: 279 and 230 patients from active and control practices respectively were eligible for analysis. No significant differences in airway function were detected between patients managed at active and control practices. There were no significant differences in healthcare resource use and disease-specific quality of life indicators as measured by the SGRQ. There were some significant differences in health status between patients managed at active practices compared with controls as measured by the SF-36.

Conclusion: Patients managed in general practice according to BTS guidelines experienced minor improvements in health status. Treatment strategy had no detectable impact on patients' airway function and healthcare resource use.

(c) 2005 General Practice Airways Group. Published by Elsevier Ltd. All rights reserved.

\footnotetext{
* Corresponding author. Tel.: +44 1923 450045; fax: +44 1923450046.

E-mail address: julian.guest@catalyst-health.co.uk (J.F. Guest).
} 


\section{Introduction}

Chronic obstructive pulmonary disease (COPD) is a chronic condition causing persistent and progressive breathlessness which can greatly impair the ability to lead a normal life. Smoking is the major risk factor and nearly all sufferers are over 35 years of age [1]. The prevalence of diagnosed COPD in the UK has been estimated at $2 \%$, and a further $2 \%$ are thought to remain undiagnosed [1]. COPD is the fifth most common cause of death in England and Wales, accounting for approximately 30,000 deaths per annum [1].

A diagnosis of COPD can only be established by objective measurement, preferably using spirometry [1,2]. Unlike asthma, airflow limitation in COPD, as measured by forced expiratory volume in one second $\left(\mathrm{FEV}_{1}\right)$, is persistently abnormal [2]. Management of COPD consumes vast healthcare resources [3]. However, treatment with bronchodilators can improve both symptoms and measured airflow limitation [4-6]. Nevertheless, treatment is largely symptomatic and many interventions are aimed at improving healthrelated quality of life (HRQL).

Several guidelines exist for the management of COPD including those by the British Thoracic Socie $\mathrm{V}$ (BTS) and European Respiratory Scoiey 'aERS) $[2,7]$. Last year, new guidetines for England and

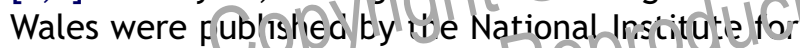
Clinical Excellence (NICE) [1]. The BUs management guidelines provide recommendations for optimum practice. However, the advice is a consensus view and it is unclear whether these recommendations lead to an improvement in the HRQL of patients. HRQL measurement is now an established method for assessing the management of patients with chronic lung disease [8]. It permits an estimate of the overall effect of treatment and can provide an indicator of the potential clinical significance of a management strategy. Accordingly, this observational study aimed to determine whether patients who are managed according to the BTS guidelines experience a better HRQL and use fewer healthcare resources than patients who are managed according to usual clinical practice.

\section{Methodology}

\section{Study design}

This was an observational, parallel group, clustercontrolled study with the primary aim of measuring the HRQL of patients with COPD who were managed in general practices according to either the BTS guidelines [2] or usual clinical practice over a period of one year. A secondary objective was to measure patients' healthcare resource use and airway function over the same period.

\section{Selection of general practices}

General practices that were computerised and had been managing patients according to either the BTS guidelines or usual clinical practice before the start of this study were identified. Of these, 13 practices managing patients according to the BTS guidelines (active practices) were randomly selected and recruited into the study via a trained respiratory nurse (qualified RGNs contracted from Innovex, Marlow, Bucks, UK). These were matched with 13 other practices in their locality who managed patients according to usual clinical practice (control practices). All eligible patients attending each practice were asked to participate in the study.

Practices were matched according to geographical location, patient demographics, proportion of patients in the nractice receiving respiratory medicine and P,ACT Clata on the number of short-actirly beta-2 agonist prescriptions per headd of population.

Practicles ive tedocated a trained respiratory murse foundertake the tasks of the study. These comprised patient identification and differential diagnosis of COPD using spirometry, obtaining patients' informed consent and helping them complete quality of life questionnaires.

\section{Patient selection}

Patients were recruited into the study between October 1999 and June 2001. Patients who were over 40 years of age, who had received three or more prescriptions for beta- 2 agonists in the preceding 6 months, and had a history of wheeze, were eligible for inclusion into the study. Eligible patients were identified by the respiratory nurse who reviewed their medical records. Patients were not eligible for inclusion into the study if they had a diagnosis of another specific respiratory illness such as cystic fibrosis, bronchiectasis or a clear history of asthma. Patients were excluded if their respiratory condition was not their primary illness or if they refused consent.

\section{Patient management}

This was an observational study and general practitioners (GPs) were not asked to change the way they managed their patients. Eligible patients 
were contacted by letter from a respiratory nurse inviting them to attend the practice. At the initial screening visit, patients who agreed to participate signed an informed consent form. At this initial visit, patients were invited to complete quality of life questionnaires and their airway function was measured. A respiratory nurse invited patients back to the practice 12 months later to complete quality of life questionnaires and to have their airway function measured. Patients were not invited back to the practice during the study period. However, patients visited their GP or practice nurse according to their individual needs and circumstances. Patients only saw the study respiratory nurse at the start and end of the study. Implementation of the BTS guidelines [2] was achieved by GPs maintaining responsibility for treatment choices and the respiratory nurses performing diagnostic tests, such as spirometry, at the screening visit.

\section{Recording patients' HRQL}

Patients completed the St. George's Respiratory Questionnaire (SGRQ) [9] and the Short Form 36 (SF36) [10] at their screening visit and 12 months later.

The SGRQ is a disease-specific, self-administered questionnaire, developed for use in clices vith chronic airflow limitation, to fecord patients' perceived teve'(c) heaith impairment reflected in terms ol symptomatology an: ineir quality of life. Individual questionnaires were completed in accordance with the SGRQ guidelines. The SGRQ produces four scores which are expressed as a percentage of overall impairment, where 100 represents the worst possible health status and 0 indicates the best possible health status. The scores are for symptoms (their frequency and severity), activity (activities that are caused or limited by breathlessness), impacts (concerned with social functioning and psychological disturbance resulting from airway disease) and total score which summarises the impact of the disease on overall health status.

The SF-36 is a general health profile questionnaire that measures health status across eight domains of health. These are: physical functioning; role-physical; bodily pain; general health; vitality; social functioning; role-emotional; and mental health. Scores are transformed to a 0-100 scale with higher scores indicating better health states. There is a further unscaled single item asking respondents about health change over the past year.

Completed quality of life questionnaires were dual-entered by different data-entry clerks into a specifically designed Access database. Upon obtaining the final 12-month questionnaires, the databases were matched and cleaned with reference to the original questionnaires.

\section{Resource use and drug utilisation}

Respiratory-related healthcare resource use and drug utilisation data during the study period were obtained from patients' case notes at a sub-group of 10 active and 7 control practices by a respiratory nurse and entered into a de-identified database that was purpose-designed for this study.

\section{Data analyses}

Patients were stratified and analysed according to whether they had been managed in active or control practices. Patients who withdrew from the study (either because they left the practice or withdrew consent) were not included in the analysis. Patients who died or did not attend their 12-month visit were also excluded from the analysis.

Patients' quality of life scpres for the two questionnaires werescilc lated following the methods rlacuriner ded by the questionnaire develepers $[9,10]$. The St George's respiratory questionnalre tis accompanied by an Excel spreadsheet called the 'SGRQ calculator.' It calculates the three component scores and a total score when data from the questionnaire is entered in the correct format. The scoring programme adjusts for up to $24 \%$ of missing items in the questionnaire. Analysis of the SF-36 questionnaires involved three stages: item recoding (for the ten items that require recoding and to deal with out-of-range values and missing data); computing scale scores by summing across items in the same scale (raw scale scores); and finally transforming raw scale scores to a $0-100$ scale.

\section{Statistical methods}

At the end of the study, 279 and 230 patients from 13 active and 13 control practices respectively were eligible for analysis. These sample sizes would have allowed us to detect up to a $5 \%$ difference in quality of life scores with 95\% power and a Type 1 error probability of $5 \%$.

This was a cluster-design study where the patients at active general practices were compared with those at control general practices. Several techniques exist for analysing data from such studies, but fundamentally it is the general practices and not patients that are the unit of the analysis [11]. Therefore, a summary statistic for 
each practice was constructed and these summary values were analysed as described by Kerry \& Bland 1997 , using a weighted two sample $t$-test to assess whether the differences between changes in quality of life scores over 12 months were significantly different between active and control practices $[12,13]$.

Patients' mean airway function, resource use and drug utilisation were quantified for each practice. A weighted two sample $t$-test was performed to assess whether the differences between patients' resource use and airway function over the study period were significantly different between active and control practices. A Chi Squared test was used to assess whether the differences between patients' drug utilisation over the study period were significant between active and control practices

\section{Ethical approval}

Approval for this study was obtained from the North Thames Multi-centre Research Ethics Committee and then from the Local Ethics Research Committees for each participating practice.

\section{Results}

Patient characteristics

At the end of the study, 279 and 230 patients from 13 active and 13 control practices respectively were eligible for analysis (Table 1). The mean age of patients managed in the active practices was 68.9 years $(95 \% \mathrm{Cl}: 68.3 ; 69.6)$ and $54 \%$ were male. The mean age of patients managed in control practices was 67.7 years $(95 \% \mathrm{Cl}: 66.6 ; 68.7)$ and $53 \%$ were male.
Twenty five percent of patients in the active practices smoked a mean 13 cigarettes per day during the study and $66 \%$ of patients had stopped smoking before the study. $22 \%$ of patients in the control practices also smoked a mean 13 cigarettes per day during the study and $72 \%$ of patients had stopped smoking before the study.

\section{Airway function}

At the end of the study period, no significant differences in airway function were detected between patients managed at active and control practices.

The mean $\mathrm{FEV}_{1}$ at the start of the study was similar for patients managed in active and control practices $(1.33$ litres $(95 \% \mathrm{Cl}: 1.12 ; 1.54)$ and 1.27 litres $(95 \% \mathrm{Cl}: 0.79 ; 1.76)$ respectively). At the end of the study, there was a $5 \%$ and $7 \%$ decline in $\mathrm{FEV}_{1}$ values among patients managed at active and control practices (1.26 litres (95\% $\mathrm{Cl}: 1.20 ; 1.33)$ and 1.18 litres $(95 \% \mathrm{Cl}: 1.06 ; 1.30)$ respectively).

Similarly, the mean forced vical Caloacity (FVC) at the start of the gtudy was similar for patients mapaseo in active and control practices ( 2.38 litres 2(15\%) $\mathrm{Cl}: 20 \%+2.56)$ and 2.12 litres $(95 \% \mathrm{Cl}$ : $1.672^{2} .50$ ) | respectively). At the end of the $0: t$ id there was a decline of $9 \%$ and $0 \%$ in the mean FVC values among patients managed at active and control practices $(2.16$ litres $(95 \% \mathrm{Cl}$ : $2.01 ; 2.31)$ and 2.19 litres (95\% Cl: $2.00 ; 2.38$ ) respectively).

\section{Resource use}

There were no significant differences between active and control practices in patients' healthcare

Table 1 Number of patients in active and control practices.

\begin{tabular}{llr}
\hline & Number of patients & \multicolumn{1}{c}{$\begin{array}{c}\text { Control practices } \\
(n=13)\end{array}$} \\
\cline { 2 - 3 } & $\begin{array}{l}\text { Active practices } \\
(n=13)\end{array}$ & 622 \\
\hline Patients entered into the study at baseline & 844 & 107 \\
Patients excluded as non-COPD sufferers & 167 & 125 \\
Patients who withdrew from the study and withdrew & 184 & 51 \\
$\quad$ consent for their baseline data to be analysed & 32 & 339 \\
Patients who either died or left the practice & 461 & 99 \\
Patients expected to attend for the 12-month visit & 160 & 240 \\
Patients who did not attend the 12-month visit & 301 & 10 \\
Patients who actually completed the 12-month visit & 22 & 230 \\
Patients with 12-month data missing & 279 & \\
Patients eligible for analysis & & \\
\hline
\end{tabular}


Table 2 Resource use and drug utilisation during the study period.

\begin{tabular}{|c|c|c|c|}
\hline & \multicolumn{2}{|c|}{$\begin{array}{l}\text { Mean resource use ( } 95 \% \text { confidence interval) } \\
\text { and drug utilisation }\end{array}$} & \multirow{2}{*}{$\begin{array}{l}\text { Significance of difference } \\
\text { between active and } \\
\text { control practices }\end{array}$} \\
\hline & Active practices $(n=10)$ & Control practices $(n=7)$ & \\
\hline Number of GP visits & $1.47(0.55 ; 2.34)$ & $2.16(0.26 ; 1.78)$ & $p=0.264$ \\
\hline Number of nurse visits & $0.69(0.15 ; 0.64)$ & $0.67(0.18 ; 0.19)$ & $p=0.936$ \\
\hline Number of outpatient referrals & $0.21(0.09 ; 0.40)$ & $0.24(0.10 ; 0.65)$ & $p=0.843$ \\
\hline $\begin{array}{l}\text { Percentage of patients } \\
\text { admitted into hospital }\end{array}$ & $9.62(4.38 ; 14.86)$ & $6.20(5.28 ; 7.12)$ & $p=0.260$ \\
\hline \multicolumn{4}{|c|}{ Percentage of patients who received: } \\
\hline $\begin{array}{l}\text { Inhaled short-acting beta-2 } \\
\text { agonists }\end{array}$ & $100 \%$ & $94 \%$ & $p=0.157$ \\
\hline Inhaled corticosteroids & $95 \%$ & $81 \%$ & $p<0.01$ \\
\hline Inhaled anticholinergics & $32 \%$ & $12 \%$ & $p<0.01$ \\
\hline $\begin{array}{l}\text { Combination of inhaled } \\
\text { short-acting beta- } 2 \text { agonists } \\
\text { and anticholinergics }\end{array}$ & $19 \%$ & $12 \%$ & $p=0.392$ \\
\hline Long-acting beta-2 agonists & $4 \%$ & $29 \%$ & $p<0.001$ \\
\hline Theophylline & $15 \%$ & $1 \%$ & $p<0.001$ \\
\hline Sodium cromoglycate & $2 \%$ & $0 \%$ & $p=0.364$ \\
\hline Oral steroids & $6 \%$ & $4 \%$ & $p=0.810$ \\
\hline
\end{tabular}

resource use (Table 2). However, drug utilisation was significantly different between the practires (Table 2). In particular, significantly more patient? managed at active practic re repeived shortacting beta-? agonisct, in haled anticholinergics a tibd theophyllines than patients managed a control practices. Additionally, significantily fewer patients managed at active practices received long-acting beta- 2 agonists than patients managed at control practices.

\section{St George's reser fitory questionnaire}

Ghe componenteand total scores for the SGRQ for poth: (t) ve and control practices are shown in rable 3. Differences between the active and control practices are shown in Figure 1. Patients managed in both active and control practices experienced a significant improvement in their symptom score $(p<0.01)$ over the study period. The mean active score went from 64.4 to 57.6 and mean

Table 3 Transformed SGRQ scores.

\begin{tabular}{lll}
\hline Health domain & \multicolumn{2}{c}{ Weighted mean transformed SGRQ scores $(95 \%$ confidence intervals) } \\
\cline { 2 - 3 } & Active practices $(n=13)$ & Control practices $(n=13)$ \\
\hline At baseline & $64.36(61.13 ; 67.59)^{\mathrm{a}}$ & $65.92(62.54 ; 69.30)^{\mathrm{d}}$ \\
Symptom score & $58.90(55.97 ; 61.83)$ & $62.83(60.00 ; 65.66)$ \\
Activity score & $34.70(31.83 ; 37.58)^{\mathrm{b}}$ & $36.67(33.54 ; 39.80)$ \\
Impacts score & $46.98(44.21 ; 49.74)^{\mathrm{c}}$ & $49.50(46.58 ; 52.41)$ \\
Total score & & \\
At 12 months & $57.56(53.71 ; 61.41)^{\mathrm{a}}$ & $60.26(53.65 ; 66.87)^{\mathrm{d}}$ \\
Symptom score & $57.40(54.90 ; 59.90)$ & $60.76(55.45 ; 66.06)$ \\
Activity score & $31.37(28.33 ; 34.40)^{\mathrm{b}}$ & $36.31(31.30 ; 41.32)$ \\
Impacts score & $43.62(40.97 ; 46.26)^{\mathrm{c}}$ & $47.69(42.61 ; 52.78)$ \\
Total score & & \\
\hline a $p<0.01$. & & \\
b $p<0.01$. & & \\
c $p<0.01$. & & \\
d $p<0.01$. &
\end{tabular}




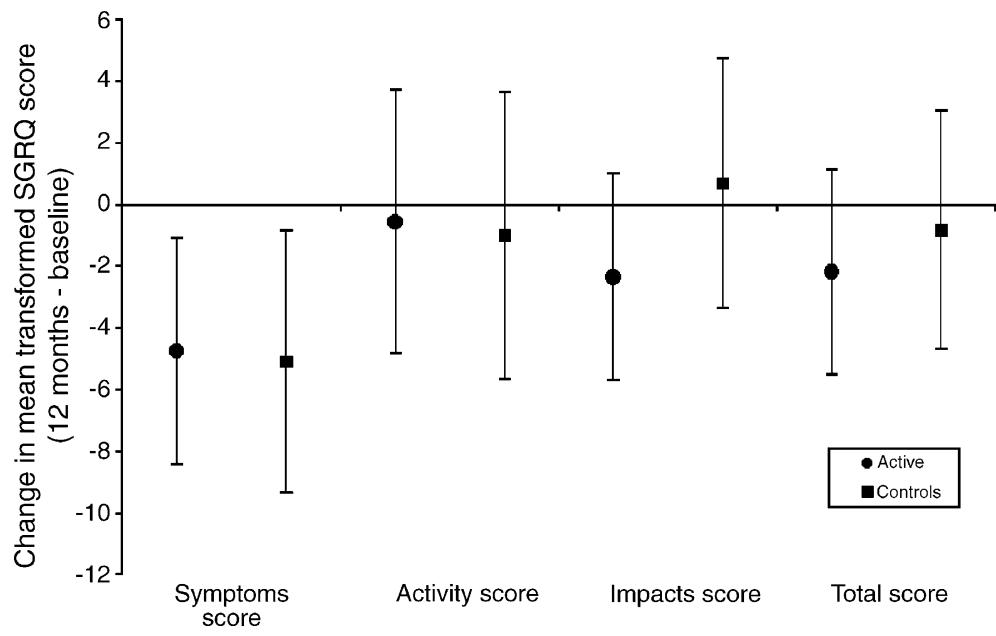

Figure 1 Differences in transformed mean SGRQ scores and 95\% confidence intervals between active and control practices.

control score went from 65.9 to 60.3 . Additionally, patients managed in active practices experienced a significant improvement in their impacts score (from 34.7 to $31.4 ; p<0.01$ ) and total score (from 47.0 to $43.6 ; p<0.01$ ) over the study period. However, there were no significant differences between the active and control practices across any of the health domains at the end of the stucly period. Moreover, Figure 1 illustrates that the upper and lower 95\% confidence values for the active and control practices overlap for all the health domains.

\section{Short form 36}

The rensformed scores for the SF-36 for both cactive and contrploctices are shown in Table 4.

Table 4 Trânsfornied SF-3ú scores.

\begin{tabular}{|c|c|c|}
\hline \multirow[t]{2}{*}{ Health domain } & \multicolumn{2}{|c|}{ Weighted mean transformed SF-36 scores ( $95 \%$ confidence intervals) } \\
\hline & Active practices $(n=13)$ & Control practices $(n=13)$ \\
\hline \multicolumn{3}{|l|}{ At baseline } \\
\hline Physical function & 48.31 (40.06; 50.55) & $47.34(42.59 ; 52.09)^{d}$ \\
\hline General health & $47.12(44.24 ; 50.00)$ & $41.84(37.00 ; 46.67)^{\mathrm{e}}$ \\
\hline Role physical & $45.24(40.45 ; 50.02)^{a}$ & $41.98(35.60 ; 48.35)$ \\
\hline Role emotional & $67.72(61.87 ; 73.57)$ & $53.18(44.08 ; 62.28)^{f}$ \\
\hline Social functioning & $74.69(71.60 ; 77.79)^{\mathrm{b}}$ & $68.15(62.28 ; 74.03)$ \\
\hline Vitality & $49.53(46.08 ; 52.98)$ & $43.83(41.46 ; 46.20)$ \\
\hline Mental health & 73.39 (71.88; 74.89) & $67.71(63.85 ; 71.57)$ \\
\hline Bodily pain & $62.53(58.44 ; 66.63)^{c}$ & $55.14(48.46 ; 61.81)$ \\
\hline \multicolumn{3}{|l|}{ At 12 months } \\
\hline Physical function & $47.79(44.80 ; 50.77)$ & $38.11(31.65 ; 44.56)^{d}$ \\
\hline General health & $47.70(43.89 ; 51.51)$ & $36.74(32.26 ; 41.22)^{e}$ \\
\hline Role physical & $52.87(46.11 ; 59.62)^{\mathrm{a}}$ & $44.49(33.89 ; 55.09)$ \\
\hline Role emotional & $68.58(65.40 ; 71.77)$ & $64.42(56.10 ; 72.75)^{f}$ \\
\hline Social functioning & $72.38(68.06 ; 76.70)^{\mathrm{b}}$ & $65.98(59.03 ; 72.93)$ \\
\hline Vitality & $48.00(44.81 ; 51.20)$ & $41.47(36.98 ; 45.95)$ \\
\hline Mental health & $73.81(71.67 ; 75.95)$ & $65.89(60.40 ; 71.38)$ \\
\hline Bodily pain & $67.47(63.90 ; 71.03)^{c}$ & $58.32(51.36 ; 65.28)$ \\
\hline $\begin{array}{l}\text { a } p<0.01 \\
\text { b } p<0.05 \\
\text { c } p<0.01 \\
\text { d } p<0.01 \\
\text { e } p<0.01 \\
\text { f } p<0.01 \text {. }\end{array}$ & & \\
\hline
\end{tabular}




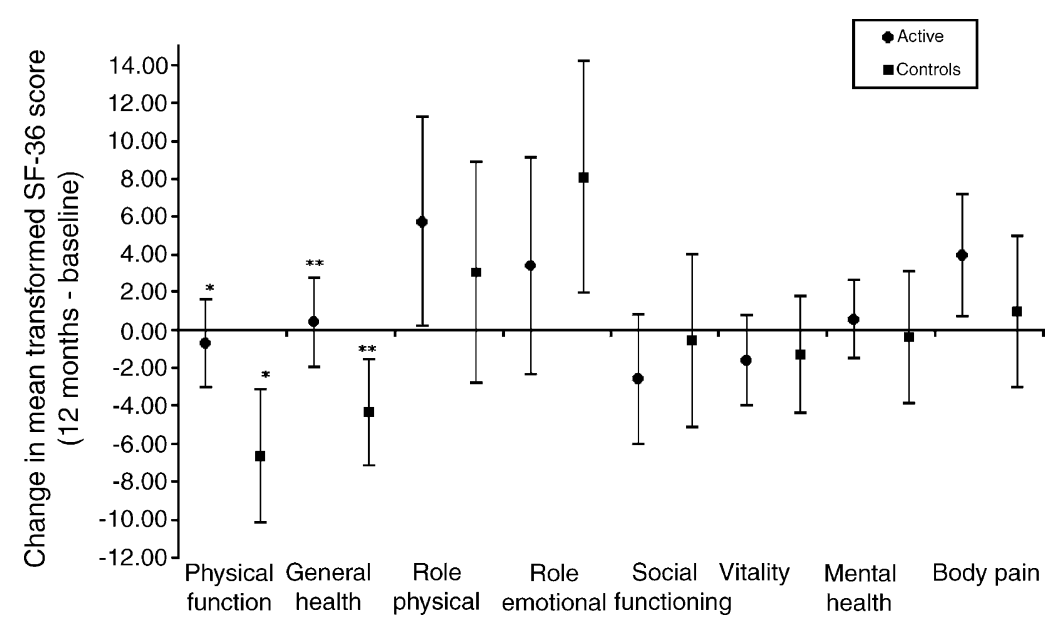

Figure 2 Differences in transformed mean SF-36 scores and 95\% confidence intervals between active and control practices. ( $\left.{ }^{*} p<0.05 ;{ }^{* *} p<0.05\right)$.

Differences between the active and control practices are shown in Figure 2. Patients managed in active practices experienced a significant improvement in their role physical score (from 45.2 to $52.9 ; p<0.01)$ and bodily pain score (from 62.5 to $67.5 ; p<0.01$ ) and a significant worsening of their social functioning score (from 74.7 to $72.4 ; p<0.05$ ) over the study period. $1 p$ contrast, patients managed in control pratices experienced a significant improveinent in their role emotional score (f) rolm 5.3.2 to 64.4: p-5.01) Gind a significant worsening in th ip vis vical function score (from 47.3 to $38.1 ; p<0.01$ ) and general health score (from 41.8 to $36.7 ; p<0.01$ ). This resulted in significant differences $(p<0.05)$ in physical function and general health scores at the end of the study period between patients managed at active and control practices. However, there were no significant differences between the active and control practices across any of the other health domains.

\section{Discussion}

This prospective, observational, parallel group, cluster-controlled study used the SGRQ and SF-36 to determine whether patients who were managed according to the BTS guidelines experienced a better HRQL than patients who were managed according to usual clinical practice, and consumed fewer healthcare resources. Thirteen active practices were recruited into the study from different regions in the UK and were each matched with a control practice in their locality. Despite the number of patients who were excluded because, for example, they were found not to have COPD or they withdrew consent, 279 patients from active practices and 230 patients from control practices were included in the final analysis. No significant differences were detected at baseline between patients who were manased (at active and control practires

T. Is vould be expected, all patients managed in the active ripatices used a short-acting beta-2 aş or is, and so too did $94 \%$ of patients managed in control practices. The majority of patients managed in both practices also used inhaled corticosteroids during the study, but significantly more patients managed at active practices did so $(p<0.01)$. Additionally, nearly one third of patients managed in active practices and just over 10\% of patients managed in control practices made use of inhaled anticholinergics $(p<0.01)$ during the study. Furthermore, $29 \%$ of patients managed in control practices required the use of a longacting beta- 2 agonist during the study compared to only $4 \%$ of patients managed according to the BTS guidelines $(p<0.001)$. Notwithstanding this, there were no significant differences in the decline in airway function between patients who had been managed according to the BTS guidelines and those who had been managed according to normal clinical practice. Moreover, there were no significant differences in healthcare resource use between active and control practices. Neither were there any significant disease-specific differences in quality of life indicators between the practices at the end of the study as measured by the SGRQ, although patients managed at both active and control practices experienced a significant improvement in their symptom score over the study period and patients managed in active practices 
also experienced a significant improvement in their impacts score. It is unclear why patients would experience an improvement in health status over the study period when their airway function declined, although other studies have found that changes in measurements of airway function $\left(\mathrm{FEV}_{1}\right.$, FVC) are not closely correlated with changes in HRQL $[14,15]$. Moreover, our findings are not consistent with those observed in the ISOLDE trial [16], which found that patients with moderate to severe COPD experienced a decline in their health status over time. However, the cohort of patients in the ISOLDE trial may be different from the cohort in our study, since our patients were older (mean 68 versus 64 years), and comprised more females ( $46 \%$ versus $26 \%$ ) and fewer smokers $(22-25 \%$ versus $36-39 \%)$.

At the end of our study, the health status of patients managed at active practices was significantly better than that of patients managed at control practices, based on their scores from the generic SF-36 instrument. This difference was due to a significant worsening in the physical function and general health domains of patients managed in control practices rather than an improvement among patients managed according to the BTS guidelines. Managing patients according to BT5 guidelines did not result in significant diffe er $c \in s$ across any other HRQL doma in cornpared to patients managed at conerdl practices. The otserren changes in 5r-36 transformec'sen ses between baseline and 12 months were less than 10 for all the domains, which, according to Wyrwich et al., suggests that the change in patients' HRQL over the study period represented clinically unimportant differences [17].

Our findings from the SF-36 instrument are broadly concordant with the findings of van Manen et al., who found that COPD particularly influences physical functioning, general health and role functioning due to physical problems [18]. However, our findings were inconsistent with those of Dheda et al. who found that implementation of the BTS guidelines produced disease-specific improvements in quality of life indicators as measured by the SGRQ at six months, but no improvement in HRQL as measured by the SF-36 [19]. Differences in the findings between the two studies may be due, in part, to the two studies having measured HRQL at different time points. Hence, the temporal impact on HRQL of managing patients according to the BTS guidelines needs to be addressed in a further study. Also, our study used much larger sample sizes than the 25 patients in the Dheda et al. study [19].

Our study has several limitations. Firstly, the BTS guidelines have been superseded by the NICE guidelines [1]. Secondly, our findings are weakened by the relatively small proportion of patients who were eligible for analysis (i.e. $41-45 \%$ of COPD patients recruited into the study). Whilst $17-20 \%$ of patients were excluded from the analysis because they were subsequently found not to have COPD, it is disappointing that $20-22 \%$ of all patients withdrew their consent for having their data analysed and a further 16-19\% did not attend for their 12-month clinic visit. The reasons for their withdrawal of consent or nonattendance are unknown, and we do not know if this cohort is similar to the patients who completed the study. However, the HRQL at baseline of those who did not attend their 12-month visit was not significantly different from those patients who completed the study. Thirdly, the lack of differences in healthcare resource use by active and control practices may reflect an insufficient number of practices included in the data set, since resource use was only collected from 10 active and 7 control practices. Fourthly, the general practices were not randomised to treatment. Hence, the study may be confounded by variations in nrimary care expertise in COPD between active arid Conirol practices. Moreover, the and as s was unable to consider the jinct act octher factors that may affect the results, such as differstres between patients in terms of cisease severity, and access to other services such as secondary care and smoking cessation. Nevertheless, practices were matched according to geographical location, patient demographics, proportion of patients in the practice receiving respiratory medicine, and PACT data on the number of short-acting beta- 2 agonist prescriptions per head of population. Finally, while the SGRQ provides a valid and standardised estimate of the overall impact of COPD, no HRQL instrument is perfect - although scores for the SGRQ are usually normally distributed with little evidence of "floor" and "ceiling" effects [8]. Despite these weaknesses, our study indicates the impact of different COPD management strategies on patients' airway function, healthcare resource use and HRQL on a large number of patients in primary care without the selection biases associated with inclusion criteria that may arise in intervention studies.

In 2002-2003, COPD resulted in 83,000 hospital admissions, 1,000 day cases and 732,000 bed days in England. The mean age of these patients was 70 years. This level of hospitalisation accounted for $16 \%$ of all respiratory-related admissions and $17 \%$ of all respiratory-related bed days [20]. Despite the burden that COPD imposes on the health service and society in the UK [3], we were unable to find 
any studies addressing the cost effectiveness of implementing the BTS guidelines and their impact on patients' HRQL. According to the BTS COPD Consortium [21], GPs and practice nurses are still less confident about diagnosing COPD than asthma, although they know how to differentially diagnose the disease. Hence, the BTS guidelines have contributed to improving differential diagnosis of COPD, resulting in more patients receiving appropriate treatment. Against this background, our observational study suggests that patients who were managed according to the BTS guidelines experienced only minor improvements in HRQL, but no other significant benefits. In particular, the burden on the health service in terms of resource use and patients' airway function was not affected by the treatment strategy employed in primary care. Further research under controlled conditions is required to determine the relationship between treatment strategies, changes in patients' airway function and $\mathrm{HRQL}$, and whether $\mathrm{HRQL}$ is an effective measure for assessing the management of patients with COPD. It remains to be seen how the NICE guidelines will impact on health service resource use, patients' HRQL and airway function.

\section{Acknowledgements}

This study wassponsoreal financially by Rethinger Ingelheim. Weither Boehrirs se rngetheim nor Innovex have had any input into the analysis of the results or manuscript. The authors do not have any conflicts of interest that are directly relevant to the content of this manuscript.

The authors thank the following GPs for allowing their patients to participate in this study: $\mathrm{Dr}$ C Atkin, Valley Medical Centre, Stocksbridge; Dr W Badgett, St Margarets Medical Practice, Twickenham; Dr B Baskaran, Parkway Health Centre, New Addington; Dr B Caplan, Timperley Health Centre, Altrincham; Dr M Ford, Whitecliff Surgery, Blandford Forum; Dr P Gibson, Essex House Surgery, Barnes; Dr A Green, Church Lane Surgery, Boroughbridge; Dr RE Griffiths, The Somerton Surgery, Somerton; Dr I Harper, Queens Road Surgery, Wimbledon; Dr E Ho, Parchmore Medical Centre, Thornton Heath; Dr R Hook, Healdswood Surgery, Mansfield; Dr P Jackson, Glastonbury Surgery, Glastonbury; Dr P Jones, Lombard Street Surgeries, Newark; Dr P Jones, Woodhouse Medical Centre, Woodhouse; Dr W Kitto, Crystal Peaks Medical Centre, Sheffield; Dr C Lawrenson, Winters Lane, Newark; Dr L Lear, Quarter Jack Surgery, Wimborne; $\mathrm{Dr} J$ Millar, Grove House Surgery, Shepton Mallet; Dr C Norris, Park Road Medical
Practice, Shepton Mallet; Dr R Patel, Morden Hall Medical Centre, Wimbledon; Dr J Reid, Posterngate Surgery, Selby; Dr C Rushford, Vine Surgery, Street; Dr J Selwyn, The Fountain Medical Centre, Newark; Dr E Ulliott, Huthwaite Health Centre, Huthwaite; Dr R Vriend, Vine Surgery, Street; Dr S Woropay, Cannon Hill Lane Medical Practice, Wimbledon.

The authors also thank Nurse S Bowe, Nurse E Emery, Nurse $M$ Ledwidge and Nurse $M$ Scales for identifying eligible general practices and patients to participate in the study, for measuring patients' airway function, and for collecting patients' healthcare resource use and completed quality of life questionnaires.

\section{References}

[1] National Institute for Clinical Excellence. Chronic obstructive pulmonary disease. Management of chronic obstructive pulmonary disease in adults in primary and secondary care, Clinical Guideline 12 February 2004. Available on line from the NICE website at http://www. nice.org.uk/CG012NICEguideline.

[2] BTS guidelines for the maragenent of Chronic obstructive pulmonary diseras/The CoPE Guidelines Group of the Standard of Care Committee of the BTS. Thorax 1597;52(Suppl 5):S1-28.

[3] Guest JF. The anin cost of chronic obstructive pulmonary Girea the the UK's National Health Service. Dis Manag Heatth Outcomes 1999;5(2):93-100.

[4] Ferguson GT. Recommendations for the management of COPD. Chest 2000;117(2 Suppl):23S-8S.

[5] Belman MJ, Botnick WC, Shin JW. Inhaled bronchodilators reduce dynamic hyperinflation during exercise in patients with chronic obstructive pulmonary disease. Am J Respir Crit Care Med 1996;153(3):967-75.

[6] Gross NJ. Ipratropium bromide. NEJM 1998;319:113642.

[7] Ferguson GT, Cherniack RM. Management of chronic obstructive pulmonary disease. NEJM 1993;328(14):101722.

[8] Jones PW. Health status measurement in chronic obstructive pulmonary disease. Thorax 2001;56(11):880-7.

[9] Jones PW, Quirk FH, Baveystock CM. The St George's Respiratory Questionnaire. Respir Med 1991;85(Suppl B):25-31, discussion 33-7.

[10] Ware JE, Snow KK, Kosinski M, et al. SF-36 Health Survey Manual and Interpretation Guide. Boston, MA: New England Medical Center, The Health Institute; 1993.

[11] Altman DG, Bland JM. Statistics Notes. Units of analysis. BMJ 1997;314:1874.

[12] Kerry SM, Bland JM. Statictics Notes: analysis of a trial randomised in clusters. BMJ 1997;316:54.

[13] Bland JM, Kerry SM. Statistics notes: Weighted comparison of means. BMJ 1998;316:129-32.

[14] Guyatt GH, Berman LB, Townsend M, et al. A measure of quality of life for clinical trials in chronic lung disease. Thorax 1987;42:773-8.

[15] Hay JG, Stone P, Carter J, et al. Bronchodilator reversibility, exercise performance and breathlessness in stable chronic obstructive pulmonary disease. Eur Respir J 1992;5:659_ 64. 
[16] Burge PS, Calverley PMA, Jones PW, et al. Randomised, double blind, placebo controlled study of fluticasone propionate in patients with moderate to severe chronic obstructive pulmonary disease: the ISOLDE trial. BMJ 2000;320:1297-303.

[17] Wyrwich KW, Fihn SD, Tierney WM, et al. Clinically important changes in health-related quality of life for patients with chronic obstructive pulmonary disease: an expert consensus panel report. J Gen Intern Med 2003;18(3):196-202.

[18] van Manen JG, Bindels PJ, Dekker FW, et al. The influence of COPD on health-related quality of life independent of the influence of comorbidity. J Clin Epidemiol 2003;56(12):1177-84.
[19] Dheda K, Crawford A, Hagan G, et al. Implementation of British Thoracic Society guidelines for acute exacerbation of chronic obstructive pulmonary disease: impact on quality of life. Postgrad Med J 2004;80(941):169-71.

[20] Department of Health 2004. Hospital Episode Statistics 2002/03. Available on line at http://www.dh.gov.uk/ PublicationsAndStatistics/Statistics/ HospitalEpisodeStatistics/fs/en.

[21] Halpin DMG, Rudolf $M$ on behalf of the BTS COPD Consortium. Implementing the BTS COPD Guidelines: How far have we come? 2004. Available on-line at http://www. brit-thoracic.org.uk/copd/pdf/posters_prens/ Implementing\%20the\%20COPD.pdf.

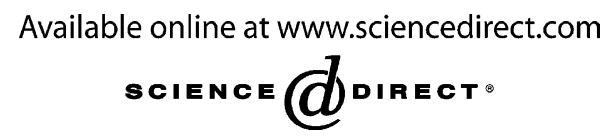

\section{Available online at http://www.thepcrj.com}

